\title{
Improved anticorrosive property of waterborne epoxy coating by ultrasonic blending with small amounts of polyaniline
}

Huan-Yan Xu ( $\nabla$ xuhuanyan@hrbust.edu.cn )

Harbin University of Science and Technology https://orcid.org/0000-0003-4895-5853

\section{Lu Zhang}

Harbin University of Science and Technology

\section{Yun-Fei Wang}

Harbin University of Science and Technology

\section{Xu Han}

Harbin University of Science and Technology

\section{Research Article}

Keywords: Waterborne epoxy coating, Polyaniline, Anticorrosion, Electrochemical analysis, Salt spray test

Posted Date: June 9th, 2021

DOI: https://doi.org/10.21203/rs.3.rs-599291/v1

License: (9) This work is licensed under a Creative Commons Attribution 4.0 International License.

Read Full License

Version of Record: A version of this preprint was published at Journal of the Iranian Chemical Society on January 20th, 2022. See the published version at https://doi.org/10.1007/s13738-021-02475-7. 


\section{Improved anticorrosive property of waterborne epoxy coating by}

2 ultrasonic blending with small amounts of polyaniline

3 Huan-Yan Xu*, Lu Zhang, Yun-Fei Wang, Xu Han

4 School of Materials Science and Chemical Engineering, Harbin University of Science and Technology,

$5 \quad$ Harbin 150040, P. R. China

$6 *$ Corresponding author

7 Tel: +86-451-86392501; Fax: +86-451-86392555

8 E-mail address: xuhuanyan@hrbust.edu.cn (H.-Y. Xu)

9 ORCID: 0000-0003-4895-5853

\section{Abstract}

11 In order to improve the anticorrosive performance of waterborne epoxy (WEP) coating, small amounts of polyaniline (PANI) were blended under ultrasonic irradiation to obtain PANI/WEP composite coatings with high dispersibility of PANI particles. The PANI/WEP composite coatings were characterized by Fourier transform infrared spectroscopy (FTIR) and field emission scanning electron microscopy (FESEM). Their adhesive force level and hardness grade were tested based on the Chinese National Standard GB/T9286-1998 and GB/T6739-1996, respectively. These results indicated that, compared to the pristine WEP coating, the addition of PANI with suitable content could completely fill the micropores or microcracks and remarkably improve the hardness grade of composite coatings. The electrochemical impedance spectra (EIS) and Tafel polarization curves revealed that the addition of PANI not only could increase the impedance arc, but also could increase the impedance modulus at low frequency. Then, the salt spray tests were employed to observe the anticorrosive performance of PANI/WEP composite coatings. Finally, the enhanced anticorrosive mechanism of WEP coating by the addition of small amounts of PANI was proposed and discussed. The addition of PANI with suitable content could play an important role of physical and chemical barriers to improve the anticorrosive performance of waterborne epoxy coating.

\section{Key words}

Waterborne epoxy coating; Polyaniline; Anticorrosion; Electrochemical analysis; Salt spray test

\section{Declarations}

Not applicable 
The phenomenon of metallic corrosion worldwide exists in various fields such as mechanical equipment, bridge construction, chemical industry, shipping and ocean engineering, which has resulted in huge economic losses and been greatly concerned by governments and enterprises [1,2]. Many methods have been attempted to protect the metallic surface against corrosion, for example, polymeric coatings [3], inorganic coatings [4], hydrid coatings [5], self-healing smart coatings [6], photocathodic protection [7] and so on. Among them, the polymeric coatings are more popularly used for the protection of metallic surface, which can form a protective barrier to inhibit the penetration of corrosive media including $\mathrm{H}_{2} \mathrm{O}, \mathrm{O}_{2}$ and other ions. Well designed polymers usually exhibit good adhensive property and stability. In addition to this, the coating technologies for polymers are simple and diverse, such as brush coating, spray coating, bar coating, roller coating, flow coating, spin coating and dip coating [8]. However, with the on-going deterioration of air environmental quality and increasing attention to human health, more and more strict laws and policies on environmental protection have been formulated by governments around the world to control and restrict the discharge of volatile organic compounds (VOCs). Therefore, the conventional solvent-based polymeric coatings are seriously suppressed and alternatively replaced by the emerging waterborne-based ones [9].

Various resins can be frequently used as waterborne coating matrix, including epoxy, acrylic, polyester, urethane and alkyd [10]. Among them, epoxy resin is extensively applied as protective coating for the metallic anticorrosion, attributed to its wide range of varieties and curing, strong adhesion,low shrinkage, excellent mechanical and electric properties, superior chemical and dimensional stability and good microbial resistance [11]. The epoxy resin coating can provide an effective protective barrier for metallic substrates and thus restrict the metallic corrosion reactions by inhibiting, shielding and cathodically protecting [12]. However, in comparison with the solvent-borne epoxy, the water-borne epoxy is not very satisfactory to act as protective coatings in practical application [13]. Suffered from a longtime exposure to extremely aggressive environment, pure epoxy resin coating will become brittle and fatigued, consequently suppressing its protection ability and further blocking its application in the anticorrosion field [14]. Furthermore, the inherent permeability of small-molecule substances $\left(\mathrm{O}_{2}, \mathrm{H}_{2} \mathrm{O}\right.$ and organic vapors $)$ and the destruction or degradation caused by mechanical or chemical effects can reduce the protective function of 
coatings [8]. In order to solve these problems, many strategies have been put forward to enhance the performance of epoxy resin coatings. To approach this goal, various organic/inorganic materials have been developed as nanofillers, including boron nitride nanosheets [12], silicon nitride nanoparticles [14], clay [15], modified graphene[16] and conducting polymers [17].

In the past few years, the conductive polymers have been increasingly employed as the additive filler in organic coatings to improve metallic anticorrosion ability, which has become a research hotspot [18]. The conductive polymers are normally constituted by conjugated electronic structures, accordingly exhibiting certain performances of both semiconductors and traditional polymers [8]. Therefore, the conductive polymers ordinarily have excellent optical, electrical and electrochemical properties and thus help to increase the corrosion protection of metallic substrates [14]. Among all the conducting polymers, polyaniline (PANI), polypyrrole (PPY), polyindole and polythiophene are more potential in the application of metallic anticorrosion [8]. And, PANI is the most fascinated by its easy preparation, environmental harmony, chemical and thermal stability, low cost, electrical conductivity, reversible redox properties and unique doping characteristics [14, 18]. Hence, PANI has been extensively used in the anticorrosive composite coatings. In general, the conductive polymers-based anticorrosive coatings can be prepared through two approaches, i. e. direct electrodeposition and blend with polymeric coating matrix. In terms of the latter, the polymeric coating blended with a small amount of conductive polymer can show better corrosion resistance than pristine coatings. However, it is difficult to obtain high solubility or dispersibility of conductive polymers in the polymeric coating matrix [17]. Likewise, PANI is easy to agglomerate in the matrix [18]. Undoubtedly, lower dispersibility of PANI in the matrix will result in worse anticorrosive performance of composite coatings.

In order to sweep away this obstacle, an ultrasonic blending method was adopted to realize the high dispersibility of PANI in water-borne epoxy resin (WEP) coatings with improved anticorrosive performance. The functional groups of PANI/WEP composite coatings were determined by Fourier transform infrared spectroscopy (FTIR). The surface and fracture morphologies of PANI/WEP composite coatings were observed by field emission scanning electron microscopy (FESEM). The hardness and adhesion of PANI/WEP composite coatings were analyzed as well. The electrochemical and anticorrosive performances of PANI/WEP composite coatings were analyzed by the electrochemical workstation and neutral salt spray (NSS) tests, respectively. Then, the effect of 
addition amount of PANI on the composite coating properties was discussed and the enhanced anticorrosive mechanism was put forward.

\subsection{Preparation of water-borne epoxy resin}

Firstly, water-borne epoxy resin was prepared and the procedure has been introduced in our previous paper [19]. Briefly, polyethylene glycol (PEG) and sodium persulfate (SPS) were employed as the accelerant and catalyst, respectively and added into some amount of epoxy resin (E44). When the mixture was heated to $175-185{ }^{\circ} \mathrm{C}$, the emulsifier was obtained. Then, the obtained emulsifier was mixed with deionized water and epoxy resin E44 at a certain weight proportion under magnetic stirring to prepare the water-based emulsion of epoxy resin.

\subsection{Preparation of PANI/WEP composite coatings}

A small amount of PANI powder was added into the epoxy resin emulsion as prepared above. Under the ultrasonic irradiation, the mixed products were fully blended to realize the uniform dispersion of PANI. Afterwards, polyamide as the curing agent was added and evenly stirred by mechanical agitation. After the composite product was degassed in a vacuum oven, it was painted onto a pretreated iron plate. Subsequently, the composite coating was cured at room temperature. In this study, the coatings with PANI content of 0.5, 1.0, 1.5 and 2.0 wt. \% were prepared and labeled as PANI05/WEP, PANI10/WEP, PANI15/WEP and PANI20/WEP, respectively. Otherwise, the pure WEP coating without the addition of PANI filler was prepared as the comparative sample and labeled as WEP.

\subsection{Characterization methods}

FTIR was employed to determine the functional groups of PANI/WEP composite coatings, operating on a Nicolet Nexus-470 infrared spectrometer. FESEM was used to observe the surface and fracture morphologies of coatings, operating on a FEISirion200 scanning electron microscope equipped with a digital camera. The adhesion and hardness of PANI/WEP coatings were tested based on the Chinese National Standard GB/T9286-1998 and GB/T6739-1996, respectively. A RST-3000 electrochemical workstation was utilized to analyze the electrochemical performances of composite coatings including electrochemical impedance spectroscopy (EIS) and Tafel polarization curves. NSS tests were implemented to investigate the anticorrosive performance of composite coatings by a salt spray chamber with $5 \pm 0.5 \% \mathrm{NaCl}$ solution ( $\mathrm{pH}=6.5-7.2)$ as the corrosive medium. 


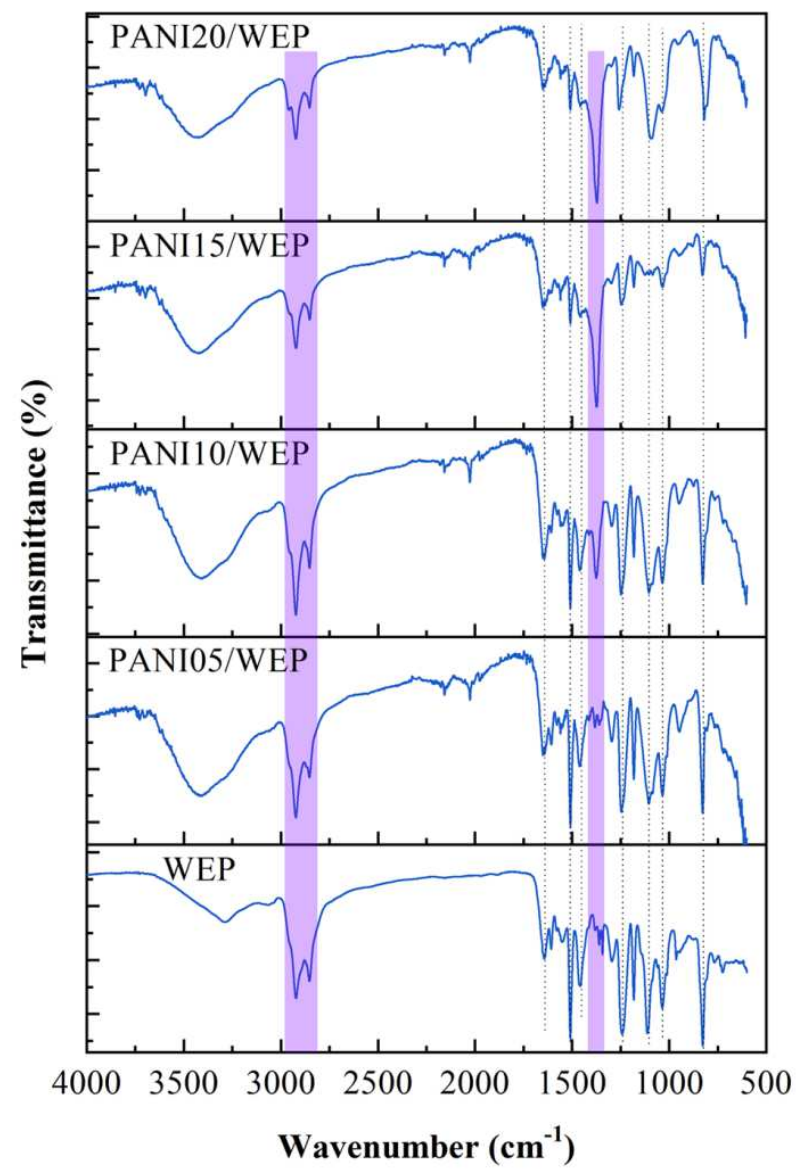

Figure $1 \mathrm{FTIR}$ spectra of WEP and PANI/WEP composite coatings

Figure 1 illustrates the FTIR spectra of WEP and PANI/WEP composite coatings, from which we can know that, for the pristine WEP coating, all the FTIR absorption peaks are assigned to the epoxy resin cured with polyamide [20]. Due to small amounts of PANI addition, its characteristic FTIR absorption peaks cannot be found in PANI/WEP composite coatings. FTIR peak positions and their assignments of these coatings are listed in Table 1 . Despite no changes in the peak positions, the intensities of certain peaks regularly vary with PANI content increasing, especially those at 2931, 2862 and $1370 \mathrm{~cm}^{-1}$. The peak intensities at 2931 and $2862 \mathrm{~cm}^{-1}$ decrease with PANI content increasing, which might be attributed to the weakened $\mathrm{N}-\mathrm{H}$ stretching vibration of amide group in polyamide structure by increasing PANI content. While, the peak intensity around $1370 \mathrm{~cm}^{-1}$ increases with PANI content increasing, probably also caused by the addition of PANI. It is well known that one of the characteristic absorption peaks of PANI appears around $1300 \mathrm{~cm}^{-1}$, assigned to the stretching vibration of $\mathrm{C}-\mathrm{N}$ of benzenoid rings in PANI structure [25-28]. Coincidentally, the 
$\mathrm{C}-\mathrm{N}$ vibration from amide group in polyamide structure occurs nearby. Therefore, the addition of

2 PANI tended to enhance the $\mathrm{C}-\mathrm{N}$ vibration and thus increase the peak intensity.

3 Table 1 FTIR peak positions and their assignments of WEP and PANI/WEP composite coatings

\begin{tabular}{|c|c|c|}
\hline FTIR peak positions $\left(\mathrm{cm}^{-1}\right)$ & Assignments & Refs. \\
\hline $3300-3400$ & -OH from hydrolyzed epoxy resin & {$[21]$} \\
\hline 2931 & \multirow{2}{*}{$\mathrm{N}-\mathrm{H}$ stretching vibration from polyamide } & \multirow{2}{*}{ [22] } \\
\hline 2862 & & \\
\hline 1652 & $\mathrm{C}=\mathrm{O}$ stretching vibration from amide group & {$[23]$} \\
\hline 1508 & aromatic rings & [22] \\
\hline 1455 & $\mathrm{C}=\mathrm{C}$ of benzene ring & {$[21]$} \\
\hline 1370 & $\mathrm{C}-\mathrm{N}$ vibration from amide group & [19] \\
\hline 1245 & epoxy groups of epoxy resin & {$[22]$} \\
\hline 1185 & \multirow{3}{*}{$\mathrm{C}-\mathrm{O}-\mathrm{C}$ bending vibration from epoxy resin } & \multirow{3}{*}{ [24] } \\
\hline 1113 & & \\
\hline 1035 & & \\
\hline 825 & epoxy groups of epoxy resin & {$[22]$} \\
\hline
\end{tabular}

4

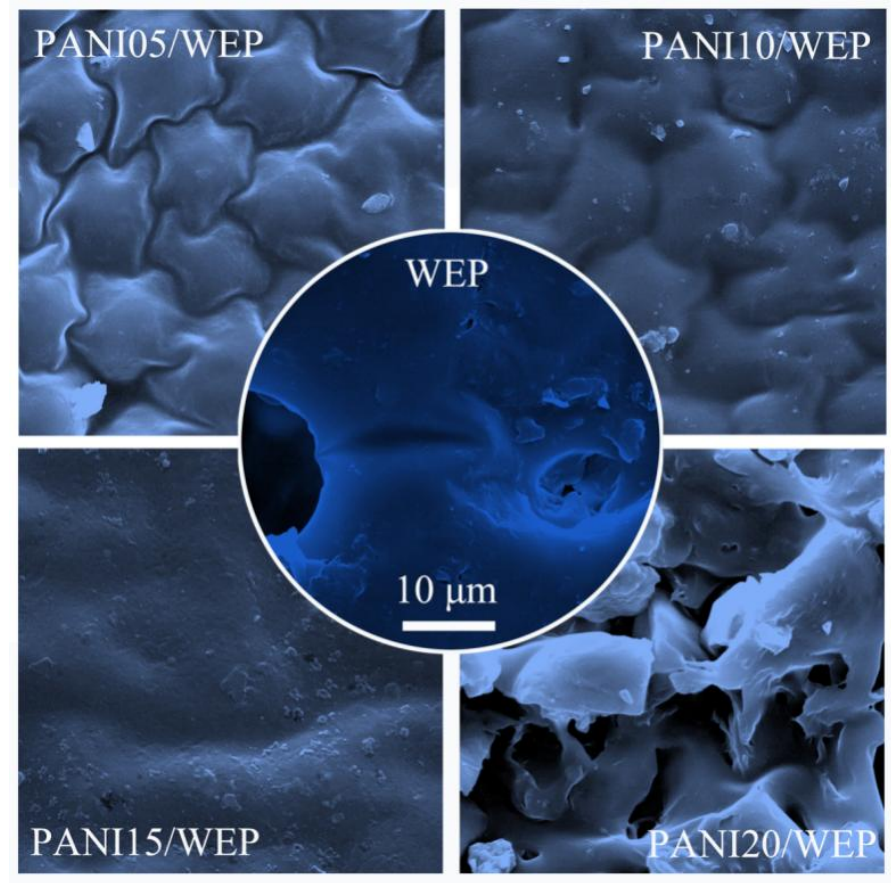

Figure 2 Surface morphologies WEP and PANI/WEP composite coatings 


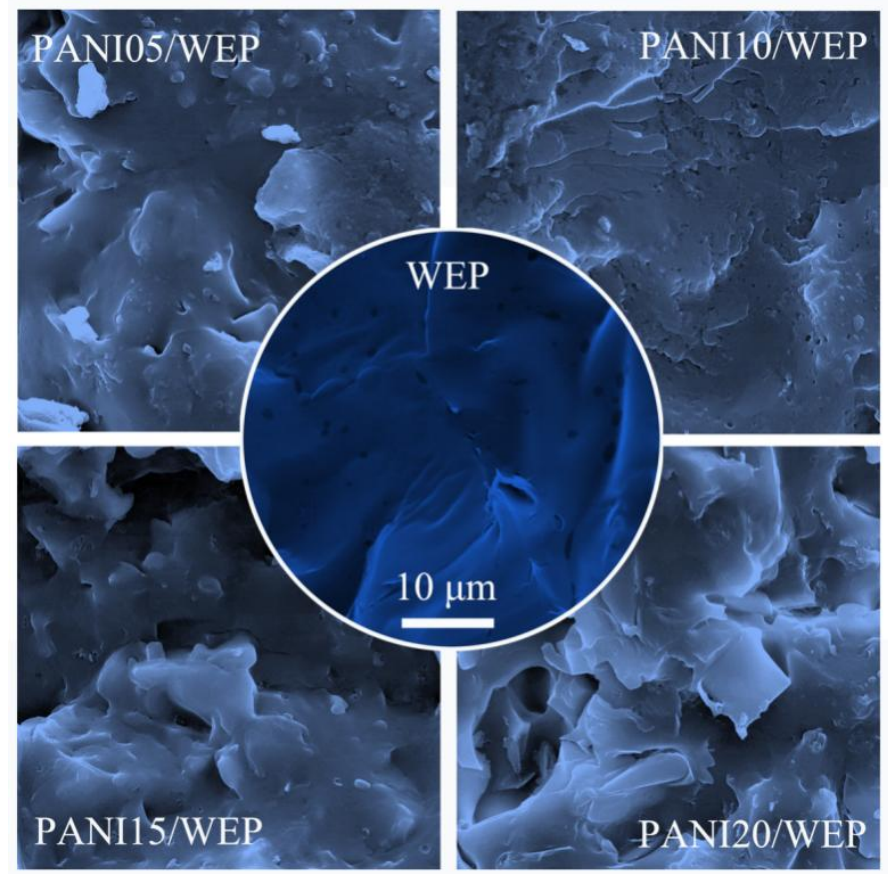

Figure 3 Fracture morphologies WEP and PANI/WEP composite coatings

The surface morphologies of WEP and PANI/WEP composite coatings are presented in Figure 2, where it can be seen that there exist many micropores in WEP coating, which might be formed during the curing process of WEP. This is an unavoidable drawback for WEP [11]. These micropores could become the tunnels for the permeability of corrosive substances, accordingly hindering the protective barrier function of WEP. After the addition of PANI with suitable content, these micropores can be filled, just like PANI05WEP, PANI10WEP and PANI15WEP coatings. However, large amounts of wrinkle-like microcracks appear in PANI05WEP coating, which will remarkably suppress its anticorrosive and mechanical performances. For PANI20WEP coating, its surface is not smooth and compact, suggesting that excessive PANI might impose restriction on the curing of WEP. Similar observation results can be seen in the fracture morphologies of WEP and PANI/WEP composite coatings, as shown in Figure 3. Many micropores appear in WEP coating and PANI particulates uniformly disperse in PANI05WEP, PANI10WEP and PANI15WEP coatings. As expected, large numbers of micropores exist in PANI20WEP coating.

Figure 4 shows the hardness grades and adhesive force levels of WEP and PANI/WEP composite coatings. According to the Chinese National Standard GB/T9286-1998 and GB/T6739-1996, PANI10WEP and PANI15WEP coatings exhibit the highest hardness grade among these five coatings and all the coatings have the adhesive force level of " 0 " that is the highest level of the given 
1 standard. These results indicate that the addition of PANI can improve the hardness grade of 2 composite coating compared to the pristine WEP coating. Due to the existence of lots of 3 microcracks or micropores in PANI05WEP and PANI20WEP coatings, their hardness grades are lower 4 than those of PANI10WEP and PANI15WEP coatings. Otherwise, the addition of PANI can not affect 5 the adhesive property of WEP.

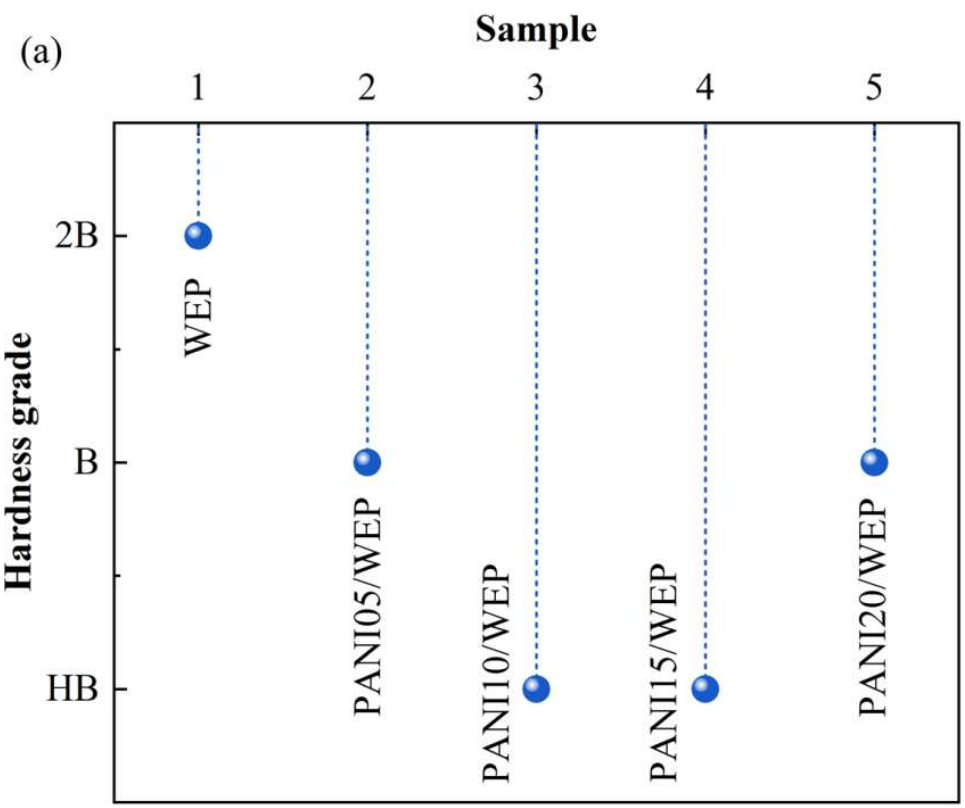

6

(b)

Sample

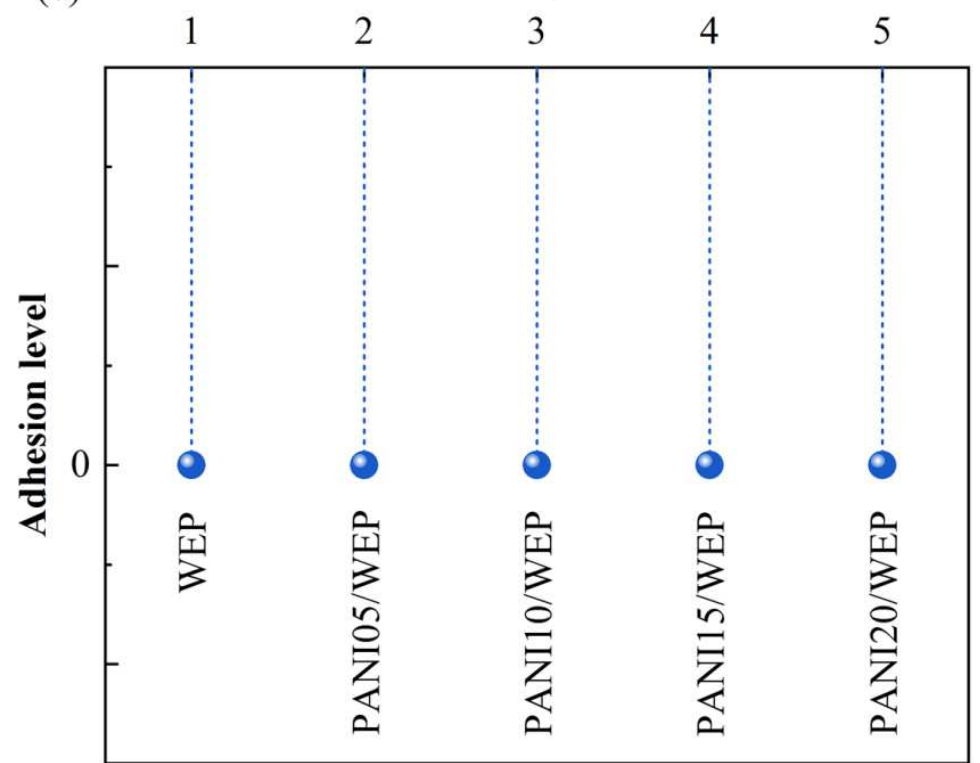

8 Figure 4 Hardness grades (a) and adhesive force levels (b) of WEP and PANI/WEP composite 9 coatings 
Generally speaking, the anticorrosive nature of a coating is closely related with its electrochemical performance. In order to have a deeper insight into the anticorrosive nature of PANI/WEP composite coatings, their electrochemical properties were characterized by Tafel polarization curve and ESI spectra in this study. Figure 5 gives the Tafel polarization curves of WEP and PANI/WEP composite coatings. Based on these curves, the corrosive potential and current density of corresponding coatings can be determined by the curve extrapolation method, i. e. the point of intersection of the straight line portions of anodic and cathodic curves [29-32]. The results are listed in Table 2, from which we can know that the addition of PANI with suitable content (0.5, 1.0 and 1.5 wt. \%) can make the corrosive potential shift towards the anodic direction and dramatically decrease the corrosive current density of the coatings. However, when the PANI content was increased to 2.0 wt. \%, the corrosive potential and current density of PANI20WEP are comparable to those of WEP. It is widely accepted that the larger corrosive potential and smaller corrosive current density indicate the better anticorrosive performance of a coating [16, 19, 31-34]. For this reason, it can be concluded that, among all the composite coatings, the anticorrosive performance of PANI15WEP is the best; while, that of PANI20WEP is the worst. The possible explanation for this phenomenon might be that PANI with suitable content can act as the filler to eliminate the micropores and microcracks in the coatings; but excessive PANI might suppress the curing of WEP and consequently generate large amounts of micropores, just as shown in the SEM images. When the micropores or microcracks were occupied, the migration pathway of corrosive substances could be interrupted and thus the corrosive potential increased and corrosive current density decreased. As a result, the anticorrosive performance of composite coatings with suitable PANI content could be improved.

Table 2 The corrosive potential and current density of different coatings obtained from Tafel curves

\begin{tabular}{ccc}
\hline Sample & Corrosive potential (V) & Corrosive current density $\left(\mathrm{A} \cdot \mathrm{cm}^{-2}\right)$ \\
\hline WEP & -1.17 & $1.55 \times 10^{-3}$ \\
\hline PANI05WEP & -0.92 & $5.89 \times 10^{-4}$ \\
\hline PANI10WEP & -0.81 & $4.90 \times 10^{-4}$ \\
\hline PANI15WEP & -0.72 & $5.75 \times 10^{-4}$ \\
\hline PANI20WEP & -1.17 & $1.48 \times 10^{-3}$ \\
\hline
\end{tabular}




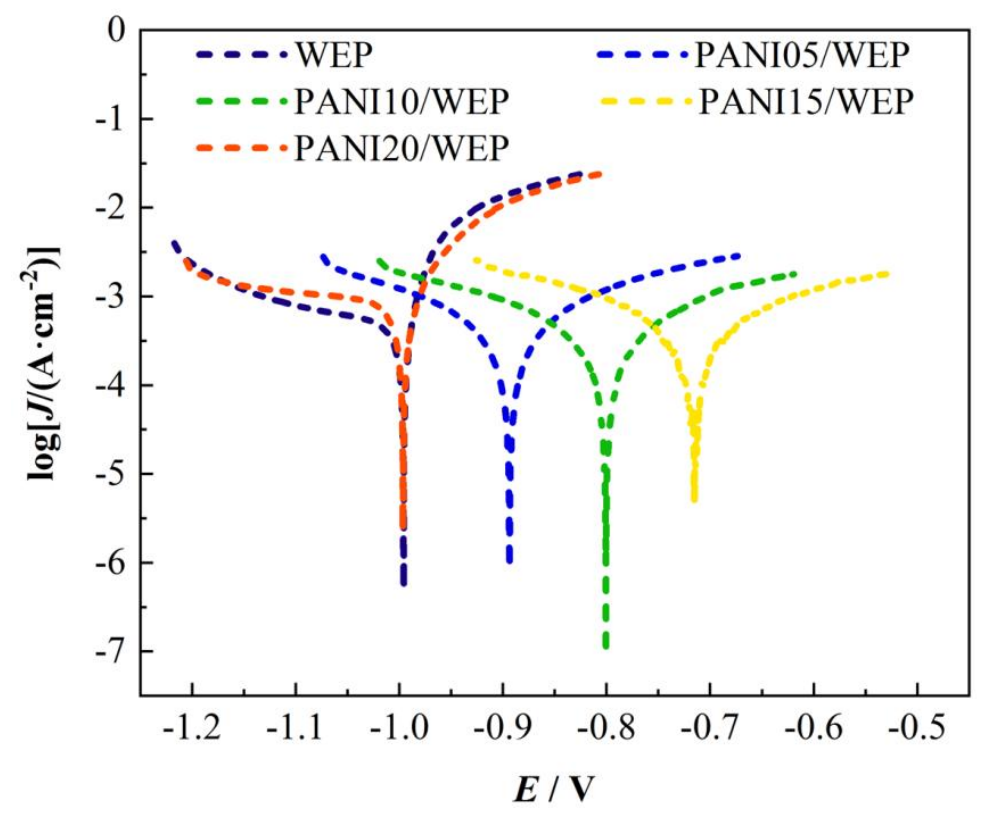

Figure 5 Tafel polarization curves of WEP and PANI/WEP composite coatings

Furthermore, EIS is another important electrochemical technique to investigate the anticorrosive nature of polymeric coatings. In this study, the impedance spectra of WEP and PANI/WEP composite coatings were obtained in $3.5 \mathrm{wt} . \% \mathrm{NaCl}$ solution at room temperature. The Nyquist plots of WEP and PANI/WEP composite coatings are presented in Figure 6, where it can be seen that all the PANI/WEP composite coatings exhibit greater impedance arc than pristine WEP coating. This means that the addition of PANI can endow these composite coatings with higher impedance against the electrochemical reactions that happened at the interface between polymeric coating and metallic substrate. PANI belongs to a kind of conducting polymer with excellent electrochemical properties and was widely used as the filler in anticorrosive coatings $[14,18]$. PANI not only acts as the protective barrier for the metallic surface, but also provides the electrochemical protection for anode and cathode related with the corrosive reactions [14]. PANI can transfer the electrons towards the interior of coating and keep them away from the coating-metal interface, accordingly impeding the redox reactions of metallic corrosion and improving the anticorrosive performance. The Bode modulus plots of WEP and PANI/WEP composite coatings are illustrated in Figure 7. The anticorrosive performance of polymeric coating can also be evaluated by the Bode modulus value at $f=0.01 \mathrm{~Hz}$. In the same way, all the PANI/WEP composite coatings have larger Bode modulus value at $f=0.01 \mathrm{~Hz}$ than pristine WEP coating. Larger Bode modulus suggests better anticorrosive performance of polymeric coating $[19,34]$. In brief, the addition of PANI not only could increase the impedance arc, but also could increase the impedance modulus at $f=0.01 \mathrm{~Hz}$. Hence, 
1 from the view point of electrochemical analyses, PANI can remarkably improve the anticorrosive

2 performance of waterborne epoxy coating.

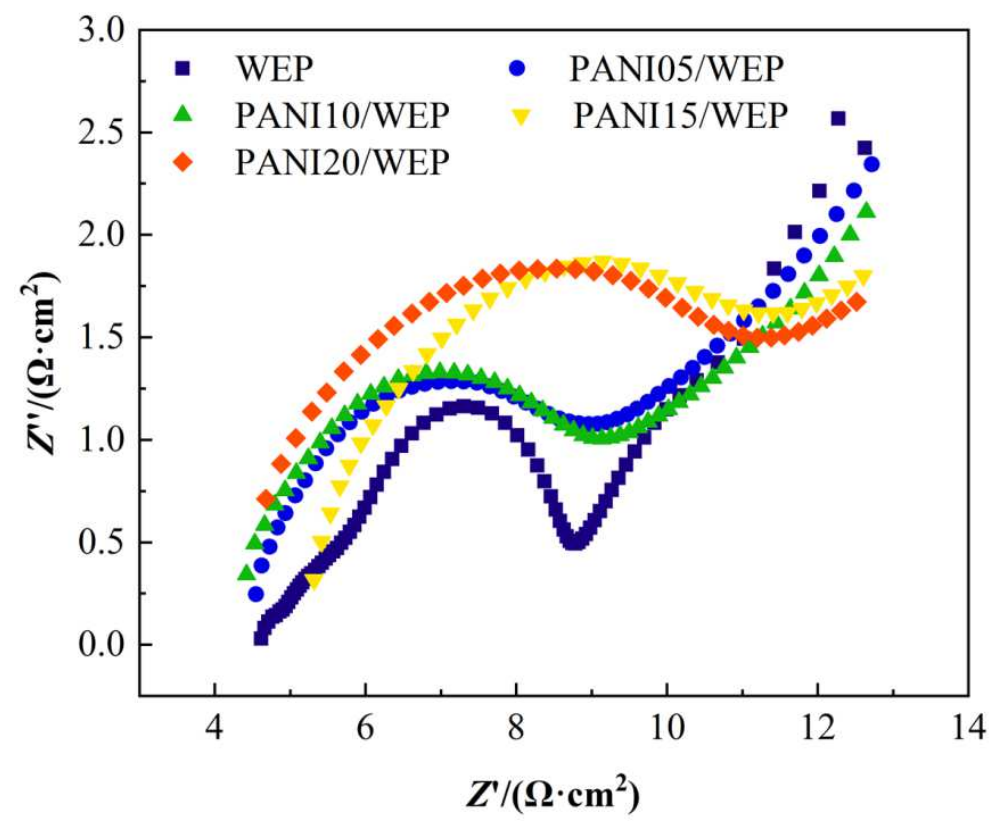

$4 \quad$ Figure 6 Nyquist plots of WEP and PANI/WEP composite coatings

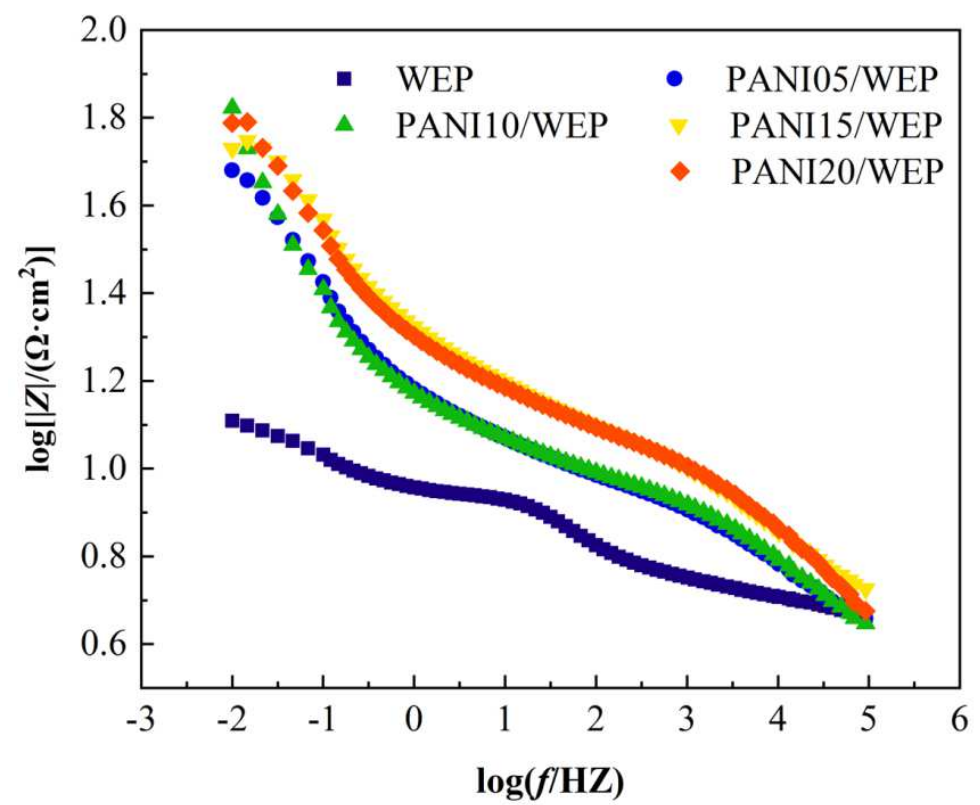

$6 \quad$ Figure 7 Bode plots of WEP and PANI/WEP composite coatings

\section{$7 \quad 3.3$ Enhanced anticorrosive mechanism of PANI/WEP coatings}

The photographs of PANI/WEP composite coatings before and after salt spray tests are displayed in Figure 8, from which we can see that the large-area brown rusty spots appear on PANI05WEP and PANI10WEP coatings after 40-hour salt spray test. In addition, the delamination on 
1 the edge of PANI20WEP coating can be observed. Therefore, PANI15WEP coating exhibits the best 2 anticorrosive performance among these composite coatings. According to the aforementioned 3 characterization and discuss, PANI15WEP coating is compact without micropores or microcracks on 4 its surface and with the uniform dispersion of PANI particles in its interior; meanwhile, PANI15WEP 5 coating has excellent electrochemical properties against the corrosive reactions, such as corrosive 6 potential, corrosive current density and electrochemical impedance.

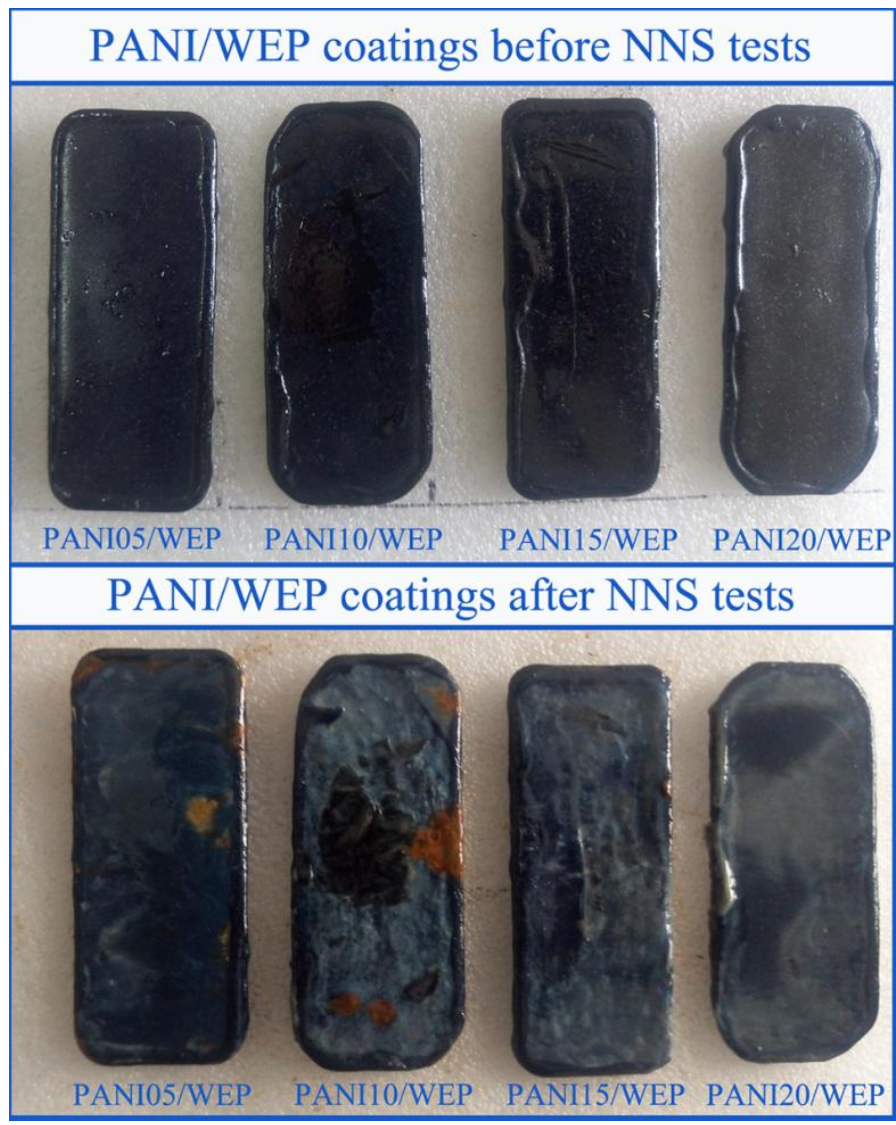

Figure 8 Photographs of PANI/WEP composite coatings before and after salt spray tests

Here, the enhanced anticorrosive mechanism of WEP coating by the addition of small amounts of PANI is proposed and illustrated in Figure 9. It has been proved that, when a low concentration of conducting polymers was added into organic coating matrix, the obtained composite coating could show better corrosion resistance than the corresponding pristine coating [17]. As a typical anticorrosive performance of polymeric coatings. However, researchers still could not reach a consensus on the enhanced anticorrosive mechanism by PANI, attributed to the complicated affecting factors such as dosage, doping, modification and redox state of PANI. Up to now, five widely accepted anticorrosive mechanisms are suggested as follows: 1) anode protection by the 
oxidation of PANI to form a new product layer on the metallic surface; 2) cathode separation by transferring the electrons generated by the corrosive reactions at the coating-metal interface to the interior of coating; 3) release of corrosion inhibitors by the doping of PANI with suitable inhibitors; 4) suppressed penetration of corrosive media by reducing the porosity to form more compact coating; and 5) electric field effect by the contact between metal and PANI to hinder the migration of electrons from metal to oxidant [35]. In this study, an ultrasonic blending method was adopted to realize the uniform dispersion of PANI particles in WEP matrix. This could guarantee the complete fill of micropores or microcracks which were probably generated during the curing or drying process. The more compact coating could play an important role in the protective barrier to suppress the penetration of corrosive media such as $\mathrm{H}_{2} \mathrm{O}, \mathrm{O}_{2}$ and other ions. This belongs to the physical barrier effect. On the other hand, PANI as a kind of conducting polymer could effectively transfer the electrons to the inside of the composite coating and accordingly interrupt the redox reactions related with metallic corrosion. At the same time, the electric field between PANI and metal could block the electron migration from metal to oxidant and thus prevent the transformation of Fe to $\mathrm{Fe}^{2+}$. These can be regarded as the chemical barrier effects. The dual barrier effect of PANI endowed the composite coatings with enhanced anticorrosive performance.
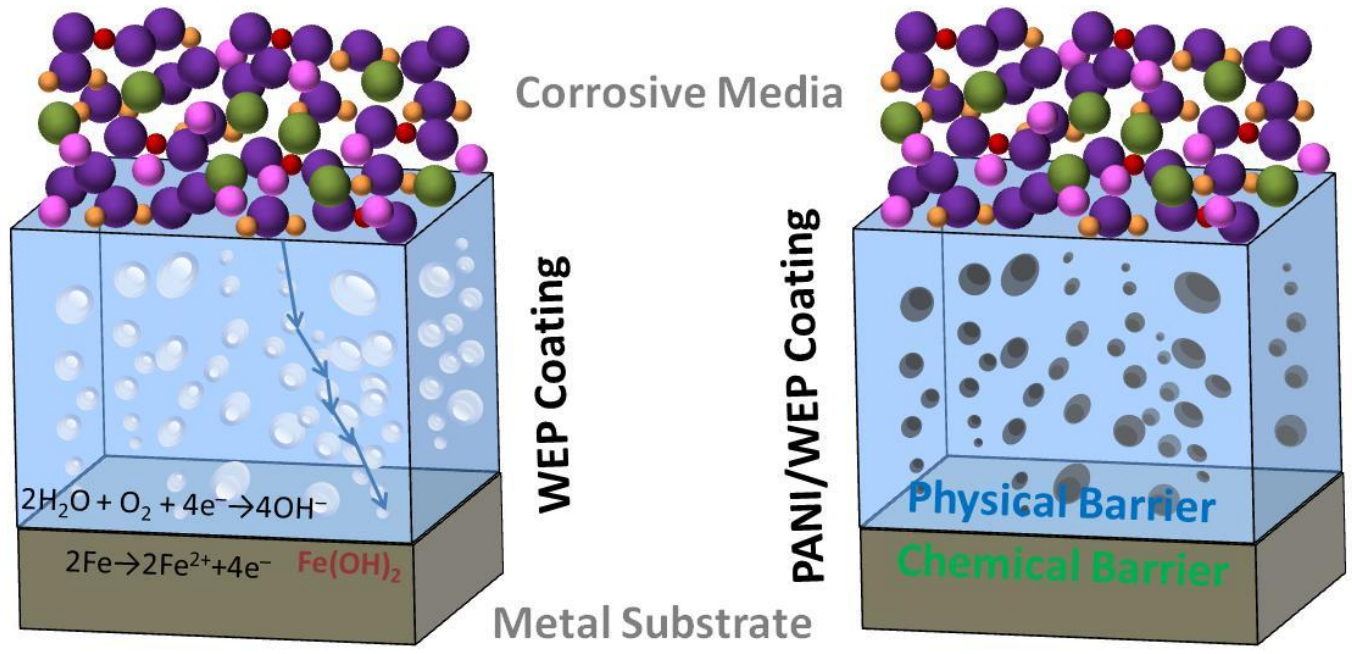

Figure 9 Enhanced anticorrosive mechanism of WEP coating by the addition of PANI

\section{Conclusions}

An ultrasonic blending method was adopted to realize the high dispersibility of PANI particles in WEP coatings with improved anticorrosive performance. There existed many micropores in WEP coating; while, after the addition of PANI with suitable content, these micropores could be filled. 
Moreover, PANI could improve the hardness grade of composite coatings compared to the pristine WEP coating. The Tafel results indicated that the addition of PANI with suitable content $(0.5,1.0$ and 1.5 wt. \%) could make the corrosive potential shift towards the anodic direction and dramatically decrease the corrosive current density of the coatings. PANI not only could increase the impedance arc, but also could increase the impedance modulus at $f=0.01 \mathrm{~Hz}$. Hence, from the view point of electrochemical analyses, PANI could remarkably improve the anticorrosive performance of waterborne epoxy coating.

\section{References}

1. Y.K. Cai, Y.M. Xu, Y. Zhao, X.B. Ma, Atmospheric corrosion prediction: a review. Corros. Rev. 38, 299-321 (2020)

2. N. Guo, Y. Wang, X.R. Hui, Q.U. Zhao, Z.S. Zeng, S. Pan, Z.W. Guo, Y.S. Yin, T. Liu, Marine bacteria inhibit corrosion of steel via synergistic biomineralization. J. Mater. Sci. Technol. 66, 82-90 (2021)

3. T. Liu, J. Wei, L. Ma, S. Liu, D. Zhang, H. Zhao, Effect of polyaniline-based plate on the anticorrosion performance of epoxy coating. Prog. Org. Coat. 151, 106109 (2021)

4. X. Yang, R.H. Zhang, J.B. Pu, Z.Y. He, L.P. Xiong, 2D graphene and h-BN layers application in protective coatings. Corros. Rev. 39, 93-107 (2021)

5. J. Zhang, Z.Y. Liu, L.H. Zhang, J. Ma, D. Sun, D. Zhang, J.R. Liu, H.N. Bai, B. Wang, Preparation of polyvinylpyrrolidone/graphene oxide/epoxy resin composite coatings and the study on their anticorrosion performance. J. Appl. Polym. Sci. 138, e50596 (2021)

6. G. Cui, Z.X. Bi, S.H. Wang, J.G. Liu, X. Xing, Z.L. Li, B.Y. Wang, A comprehensive review on smart anti-corrosive coatings. Prog. Org. Coat. 148, 105821 (2020)

7. H.X. Guo, L.L. Li, C. Su, D.M. Yu, Z.Y. Liu, Effective photocathodic protection for 304 stainless steel by $\mathrm{PbS}$ quantum dots modified $\mathrm{TiO}_{2}$ nanotubes. Mater. Chem. Phys. 258, 123914 (2021)

8. T.Y. Peng, R.H. Xiao, Z.Y. Rong, H.B. Liu, Q.Y. Hu, S.H. Wang, X. Li, J.M. Zhang, Polymer nanocomposite-based coatings for corrosion protection. Chem.-Asian J. 15, 3915-3941 (2020)

9. C.Y. Jiao, L. Sun, Q. Shao, J.Y. Song, Q. Hu, N. Naik, Z.H. Guo. Advances in waterborne acrylic resins: synthesis principle, modification strategies, and their applications. ACS Omega 6, 2443-2449 (2021) 10. Y.J. He, G. Li, K.-H. Hwang, Y. Boluk, P.M. Claesson, Nano-scale mechanical and wear properties of a corrosion protective coating reinforced by cellulose nanocrystals-Initiation of coating degradation. Appl. Surf. Sci. 537, 147789 (2021) 
11. C. Verma, L.O. Olasunkanmi, E.D. Akpan, M.A. Quraishi, O. Dagdag, M.E. Gouri, E.M. Sherif, E.E. Ebenso, Epoxy resins as anticorrosive polymeric materials: a review. React. Funct. Polym. 156, $104741(2020)$

12. D. Pan, X.D. Zhang, G. Yang, Y. Shang, F.M. Su, Q. Hu, R.R. Patil, H. Liu, C.T. Liu, Z.H. Guo, Thermally conductive anticorrosive epoxy nanocomposites with tannic acid-modified boron nitride nanosheets. Ind. Eng. Chem. Res. 59, 20371-20381 (2020)

13. M. Faccini, L. Bautista, L. Soldi, A.M. Escobar, M. Altavilla, M. Calvet, A. Domènech, E. Domí nguez, Environmentally friendly anticorrosive polymeric coatings. Appl. Sci. 11, 3446 (2021)

14. H.F. Wang, Q. Qi, Y.X. Zhang, S.G. Chen, B.B. Dong, S.D. Zhu, Q. Hu, Z.H. Guo, Anticorrosive epoxy nanocomposite coatings filled with polyaniline-functionalized silicon nitride particles. Ind. Eng. Chem. Res. 59, 16649-16659 (2020)

15. R.R. Henriques, B.G. Soares, Sepiolite modified with phosphonium ionic liquids as anticorrosive pigment for epoxy coatings. Appl. Clay Sci. 200, 105890 (2021)

16. J.H. Li, G. Niu, W. Bai, Y.J. Ma, Q.R. Xiong, C.Y. Qin, J.J. Zhang, R.H. An, W. Ren, Significant improvement of anticorrosion properties of zinc-containing coating using sodium polystyrene sulfonate noncovalent modified graphene dispersions. Coatings 10, 1150 (2020)

17. L.G. Zhang, S.H. Qiu, B. Zhu, H.C. Zhao, PEDOT-hydroxypropyl- $\beta$-cyclodextrin inclusion complex as additive for epoxy coating with enhanced anticorrosion performance. Int. J. Electrochem. Sci. 16, $210443(2021)$

18. S.Q. Yang, S. Zhu, R.Y. Hong, Graphene oxide/polyaniline nanocomposites used in anticorrosive coatings for environmental protection. Coatings 10, 1215 (2020)

19. H.Y. Xu, B. Li, X. Han, Y. Wang, X.R. Zhang, S. Komarneni, Synergic enhancement of the anticorrosion properties of an epoxy coating by compositing with both graphene and halloysite nanotubes. J. Appl. Polym. Sci. 136, 47562 (2019)

20. S. Kocaman, G. Ahmetli, A study of coating properties of biobased modified epoxy resin withdifferent hardeners. Prog. Org. Coat. 97, 53-64 (2016)

21. J.H. Liu, Q. Yu, M. Yu, S.M. Li, K. Zhao, B. Xue, H. Zu, Silane modification of titanium dioxide-decorated graphene oxide nanocomposite for enhancing anticorrosion performance of epoxy coatings on AA-2024. J. Alloy. Compd. 744, 728-739 (2018)

22. F. Ali, N. Ali, M. Altaf, A. Said, S.S. Shah, M. Bilal, Epoxy polyamide composites reinforced with 
silica nanorods: fabrication, thermal and morphological investigations. J. Inorg. Organomet. Polym. Mater. 30, 3869-3877 (2020)

23. D. Balgude, A. Sabnis, S.K. Ghosh, Investigation of cardanol-based reactive polyamide as a crosslinker in epoxy zinc-rich primer. J. Coat. Technol. Res. 14, 583-595 (2017)

24. Y. Wang, C.M. Chien, S.M. Chiao, T.Y. Lee, Reactive compatibilization of polyetherimide with polyamide 6,6: part 2. effect of epoxy-functionalized polyamide. Polym. Bull. 73, 2779-2804 (2016)

25. S. Fazli-Shokouhi, F. Nasirpouri, M. Khatamian. Epoxy-matrix polyaniline/p-phenylenediamine-functionalised graphene oxide coatings with dual anti-corrosion and anti-fouling performance. RSC Adv. 11, 11627-11641 (2021)

26. A. Alipour, M.M. Lakouraj, H. Tashakkorian. Study of the effect of band gap and photoluminescence on biological properties of polyaniline/CdS QD nanocomposites based on natural polymer. Sci. Rep. 11, 1913 (2021)

27. R.T. Liu, S.Y. Zhang, C. Zhao, D. Yang, T.T. Cui, Y.D. Liu, Y.G. Min, Regulated surface morphology of polyaniline/polylactic acid composite nanofbers via various inorganic acids doping for enhancing biocompatibility in tissue engineering. Nanoscale Res. Lett. 16, 4 (2021)

28. I. Hasan, I.I. BinSharfan, R.A. Khan, A. Alsalme, L-ascorbic acid-g-polyaniline mesoporous silica nanocomposite for efficient removal of crystal violet: a batch and fixed bed breakthrough studies. Nanomaterials 10, 2402 (2020)

29. C.-H. Chang, T.-C. Huang, C.-W. Peng, T.-C. Yeh, H.-I. Lu, W.-I. Hung, C.-J. Weng, T.-I. Yang, J.-M. Yeh, Novel anticorrosion coatings prepared from polyaniline/graphene composites. Carbon 50, 5044-5051 (2012)

30. D. Prasai, J.C. Tuberquia, R.R. Harl, G.K. Jennings, K.I. Bolotin, Graphene: corrosion-inhibiting coating. ACS Nano 6, 1102-1108 (2012)

31. N.K. Rawat, A. Ghosal, S. Ahmad, Influence of microwave irradiation on various properties of nanopolythiophene and their anticorrosive nanocomposite coatings. RSC Adv. 4, 50594-50605 (2014)

32. W. Shang, F. Wu, Y. Wen, C. He, X. Zhan, Y. Li, Corrosion resistance and mechanism of graphene oxide composite coatings on magnesium alloy. Ind. Eng. Chem. Res. 58, 1200-1211 (2019)

33. H. Guo, B. Chao, Z. Zhao, D. Nan, Preparation of aniline trimer modified graphene oxide new composite coating and study on anticorrosion performance Mater. Res. Express 7, 125601 (2020) 
1 34. H.Y. Xu, D. Lu, X. Han, Graphene-induced enhanced anticorrosion performance of waterborne 2 epoxy resin coating. Front. Mater. Sci. 14, 211-220 (2020)

3 35. F.J. Gao, J. Mu, Z.X. Bi, S. Wang, Z.L. Li, Recent advances of polyaniline composites in 4 anticorrosive coatings: a review. Prog. Org. Coat. 151, 106071 (2021) 5 6 
Figures

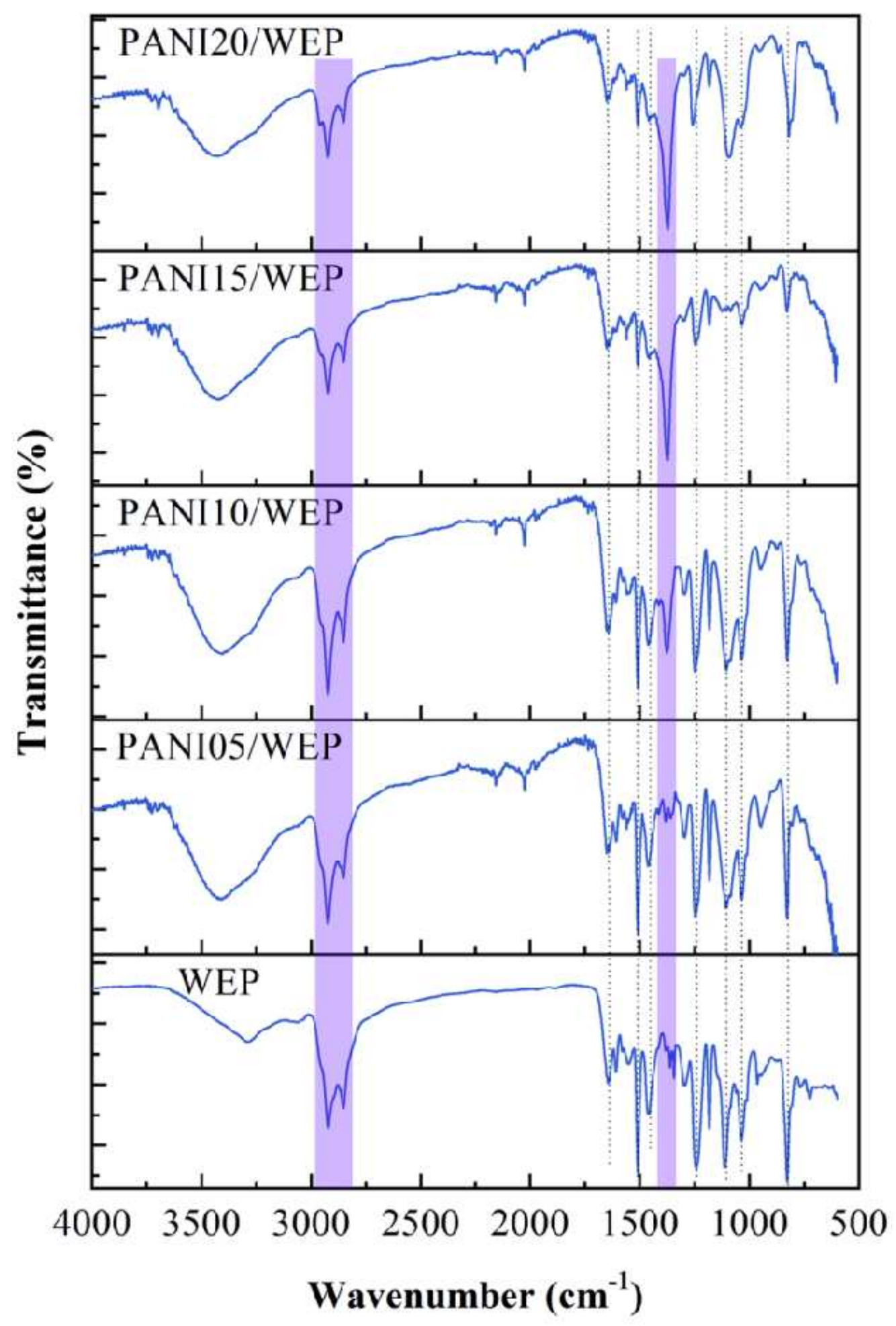

Figure 1

FTIR spectra of WEP and PANI/WEP composite coatings 


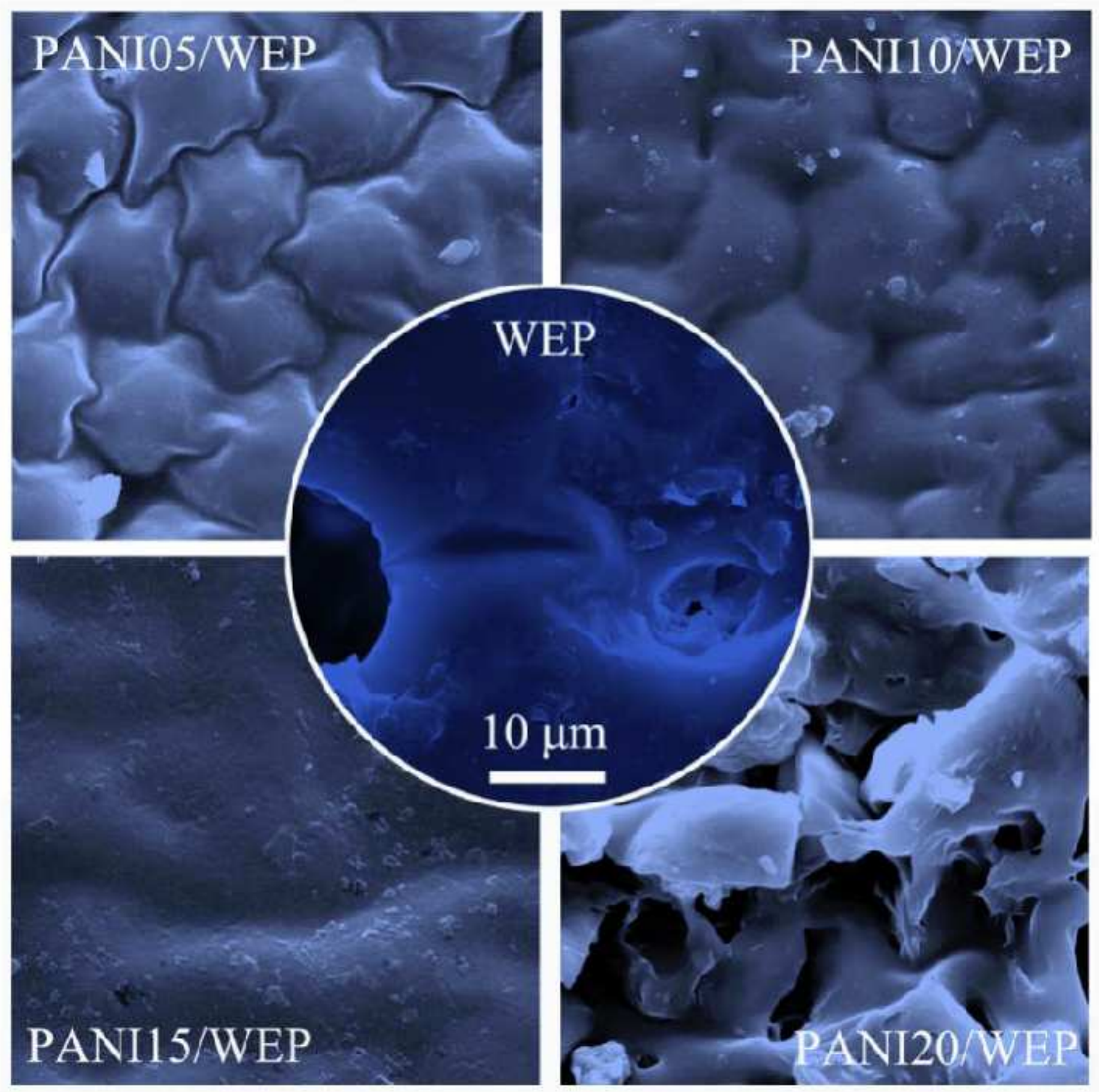

Figure 2

Surface morphologies WEP and PANI/WEP composite coatings 


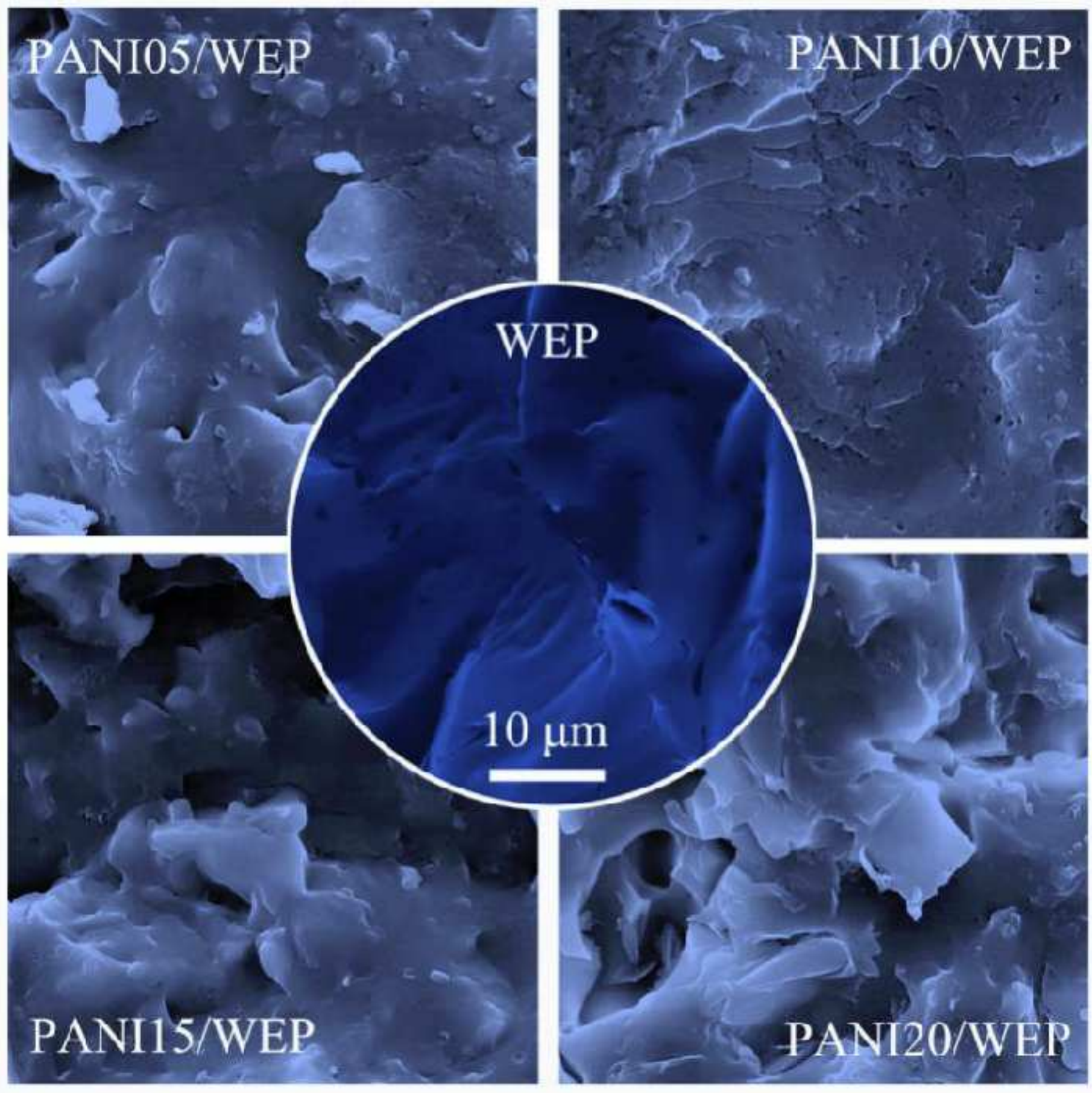

Figure 3

Fracture morphologies WEP and PANI/WEP composite coatings 


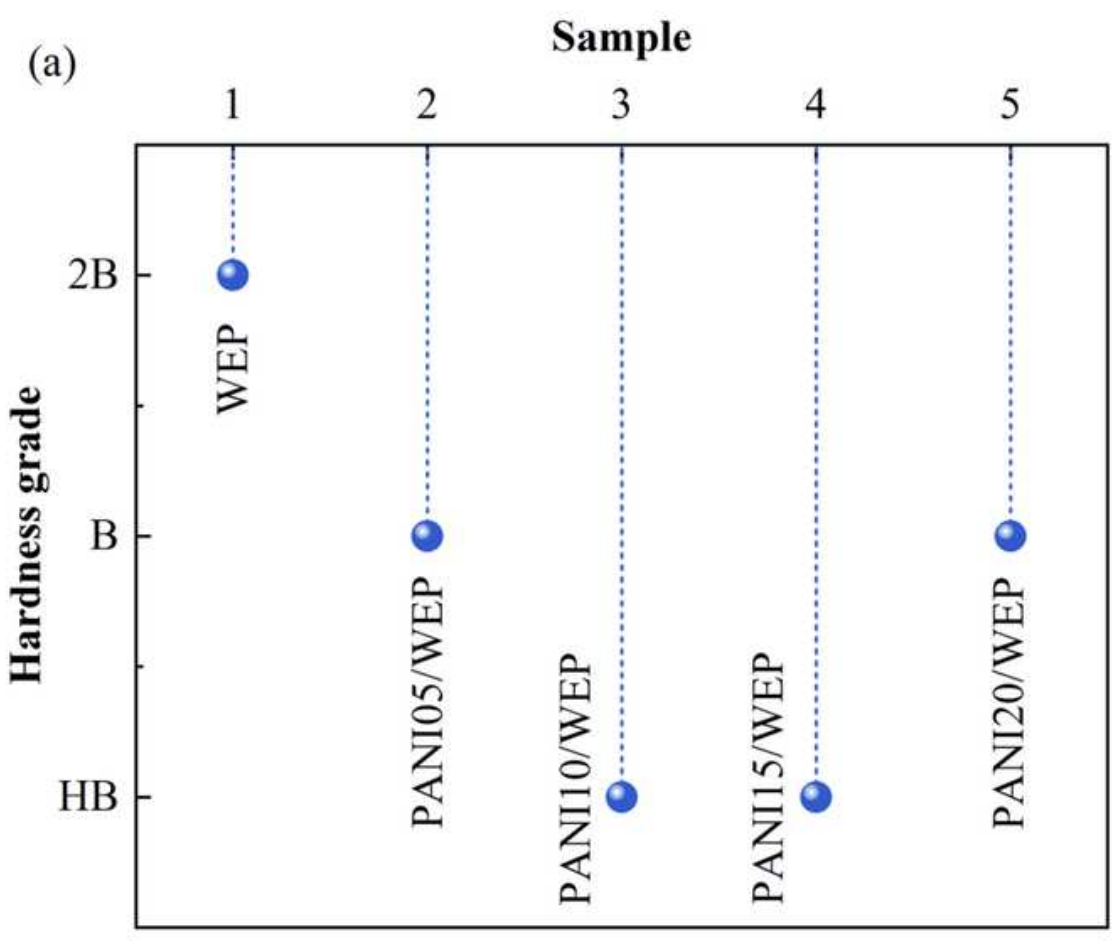

(b)

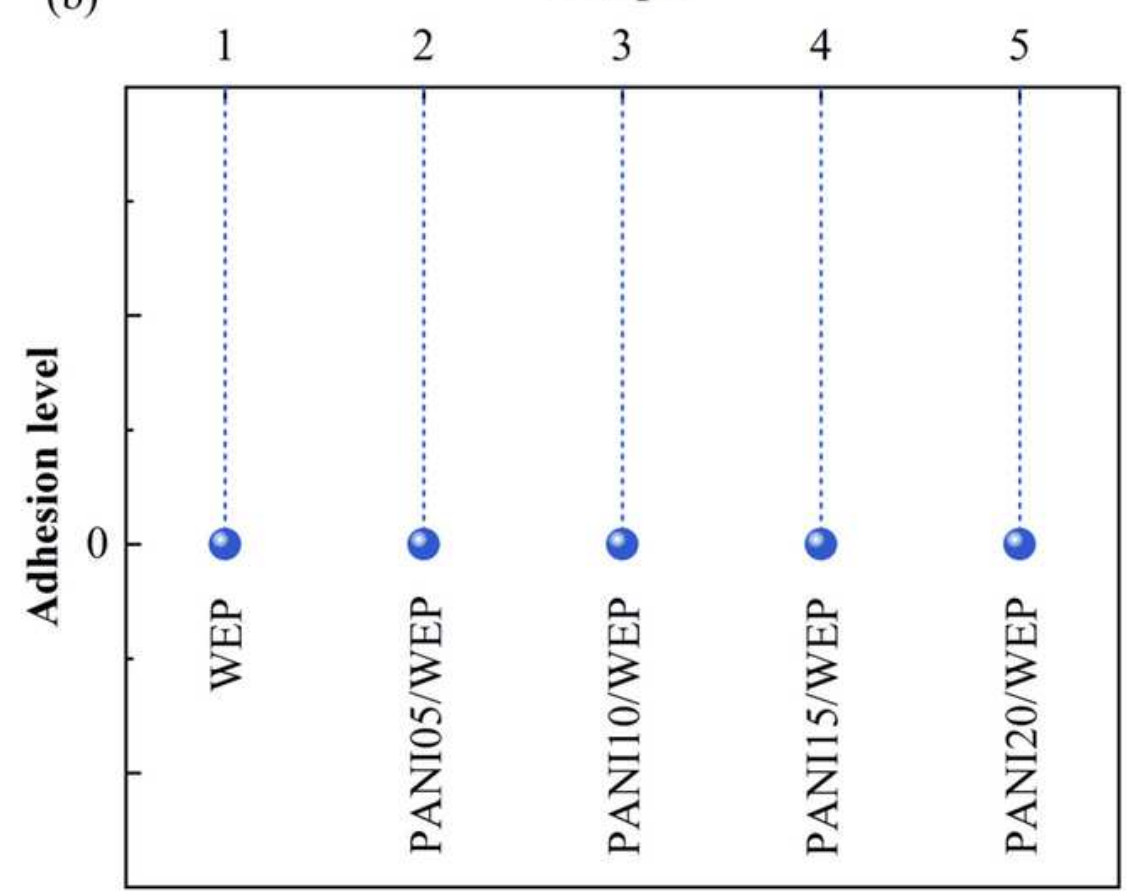

Figure 4

Hardness grades (a) and adhesive force levels (b) of WEP and PANI/WEP composite coatings 


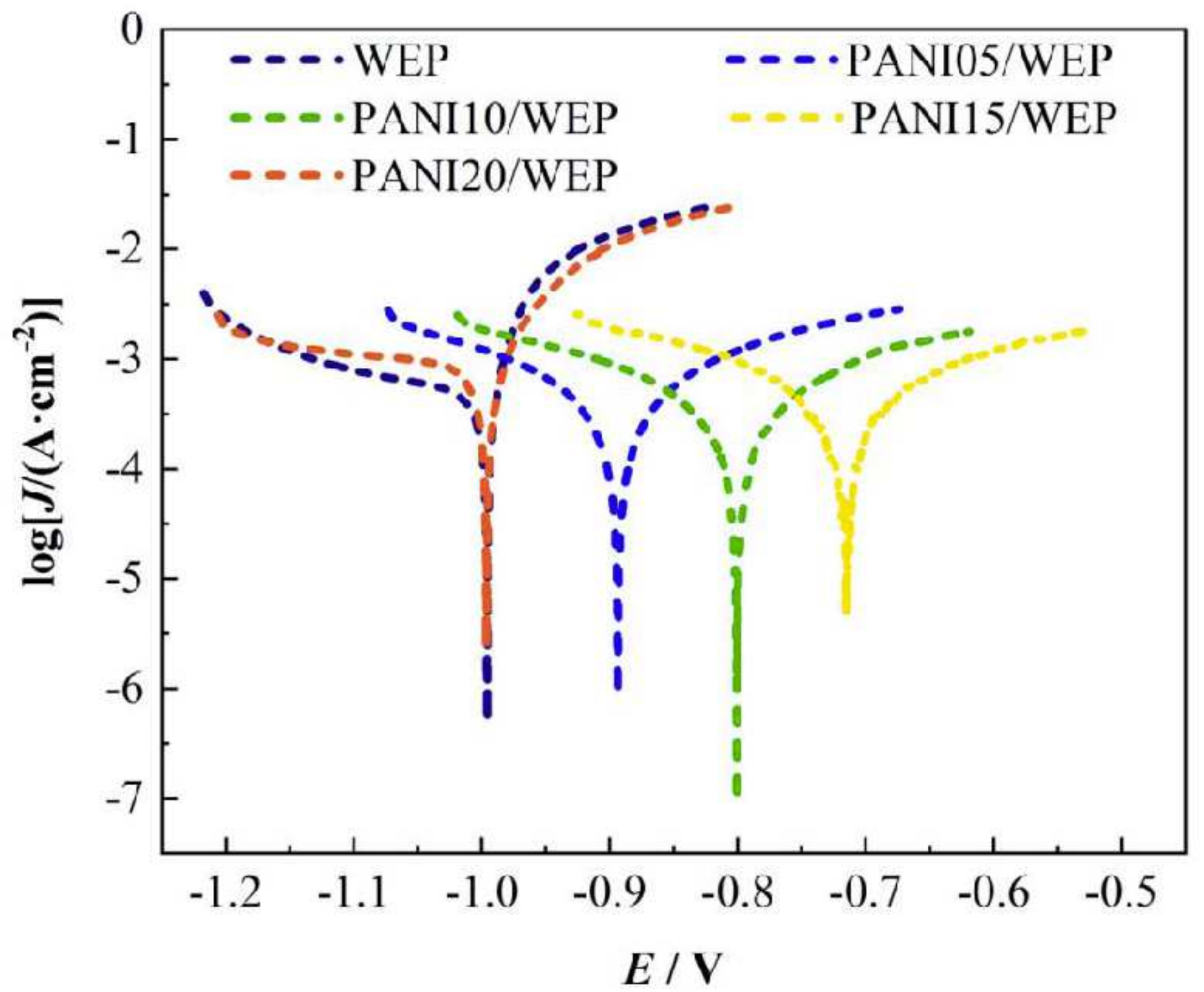

Figure 5

Tafel polarization curves of WEP and PANI/WEP composite coatings 


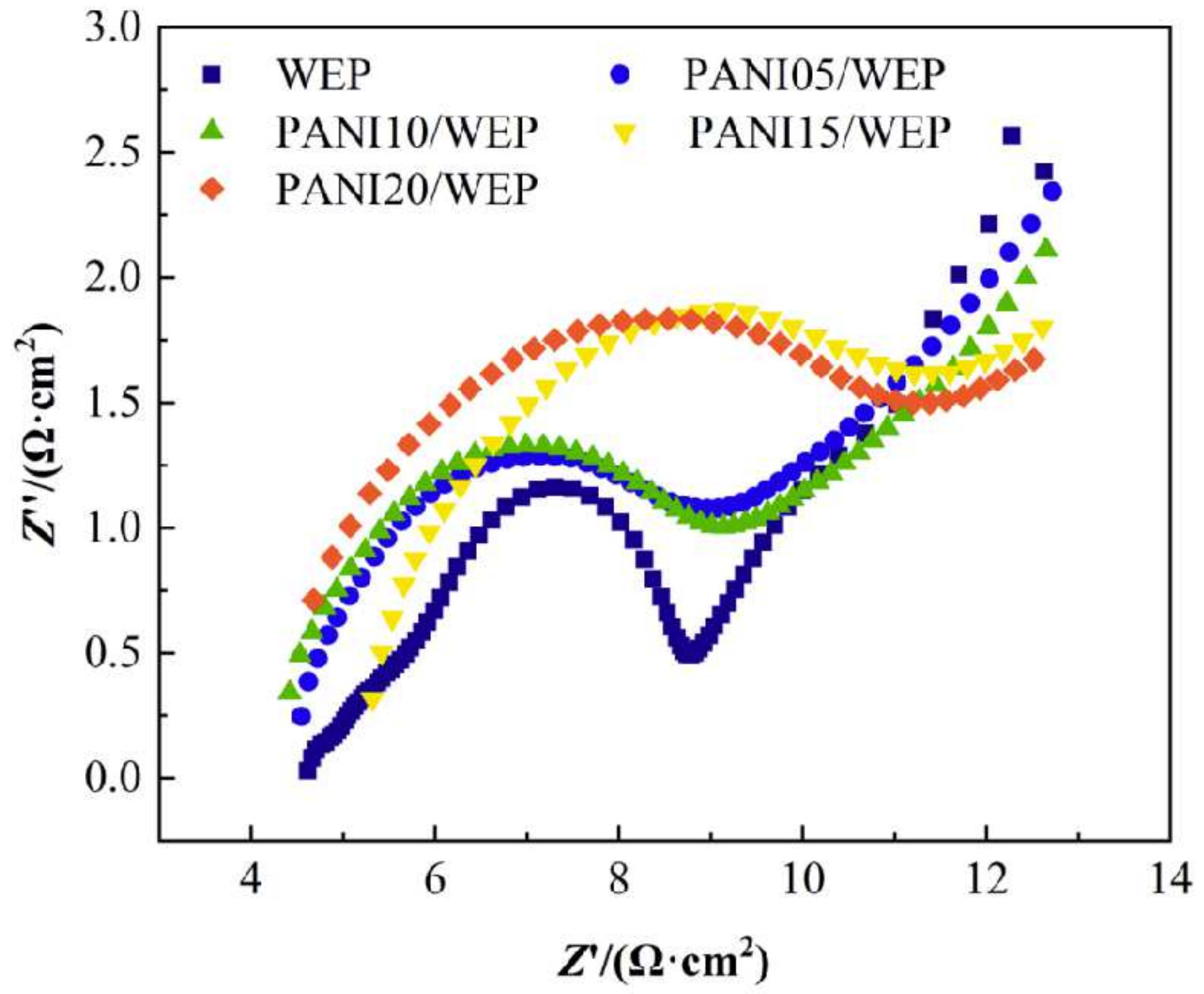

Figure 6

Nyquist plots of WEP and PANI/WEP composite coatings 


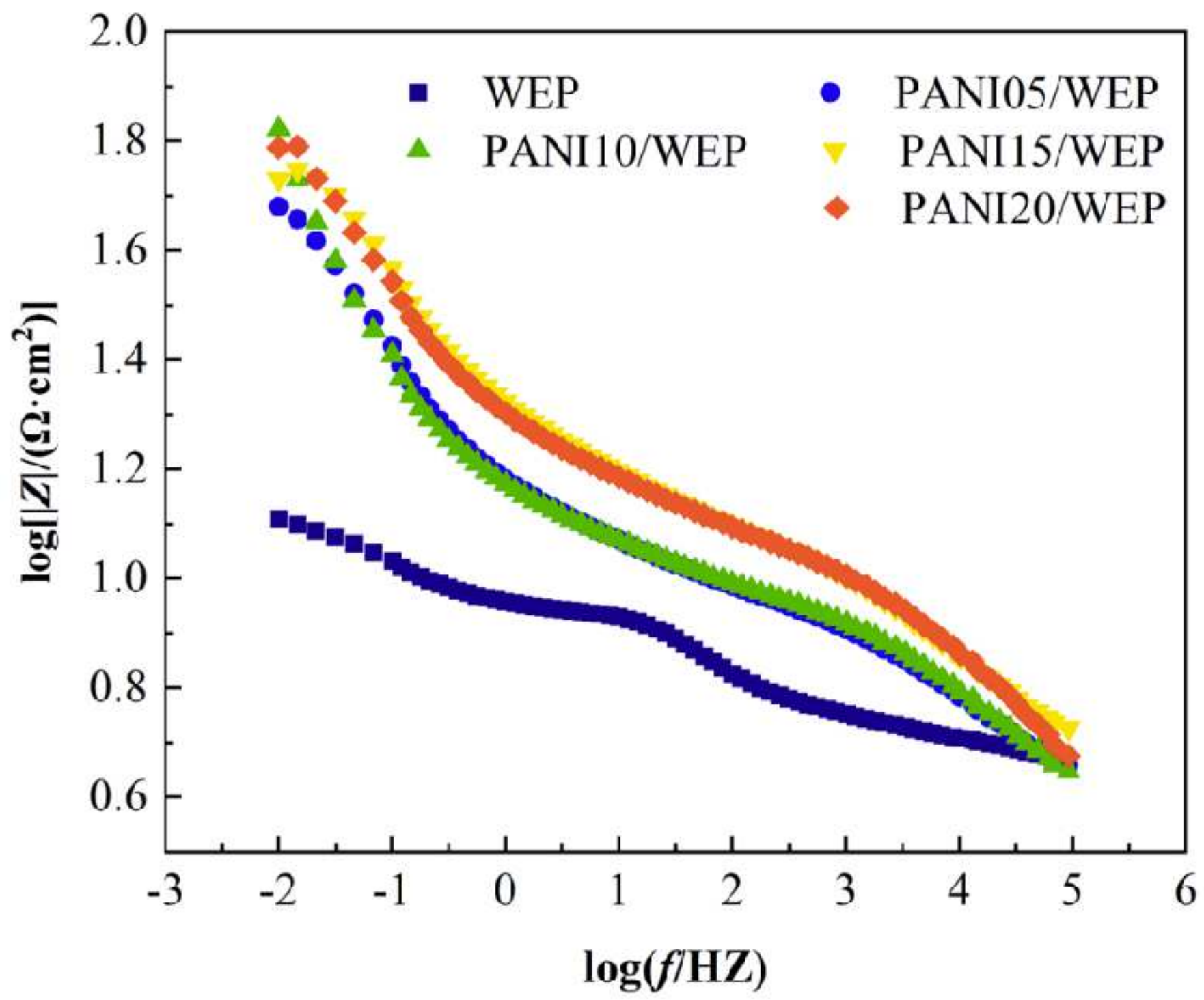

Figure 7

Bode plots of WEP and PANI/WEP composite coatings 


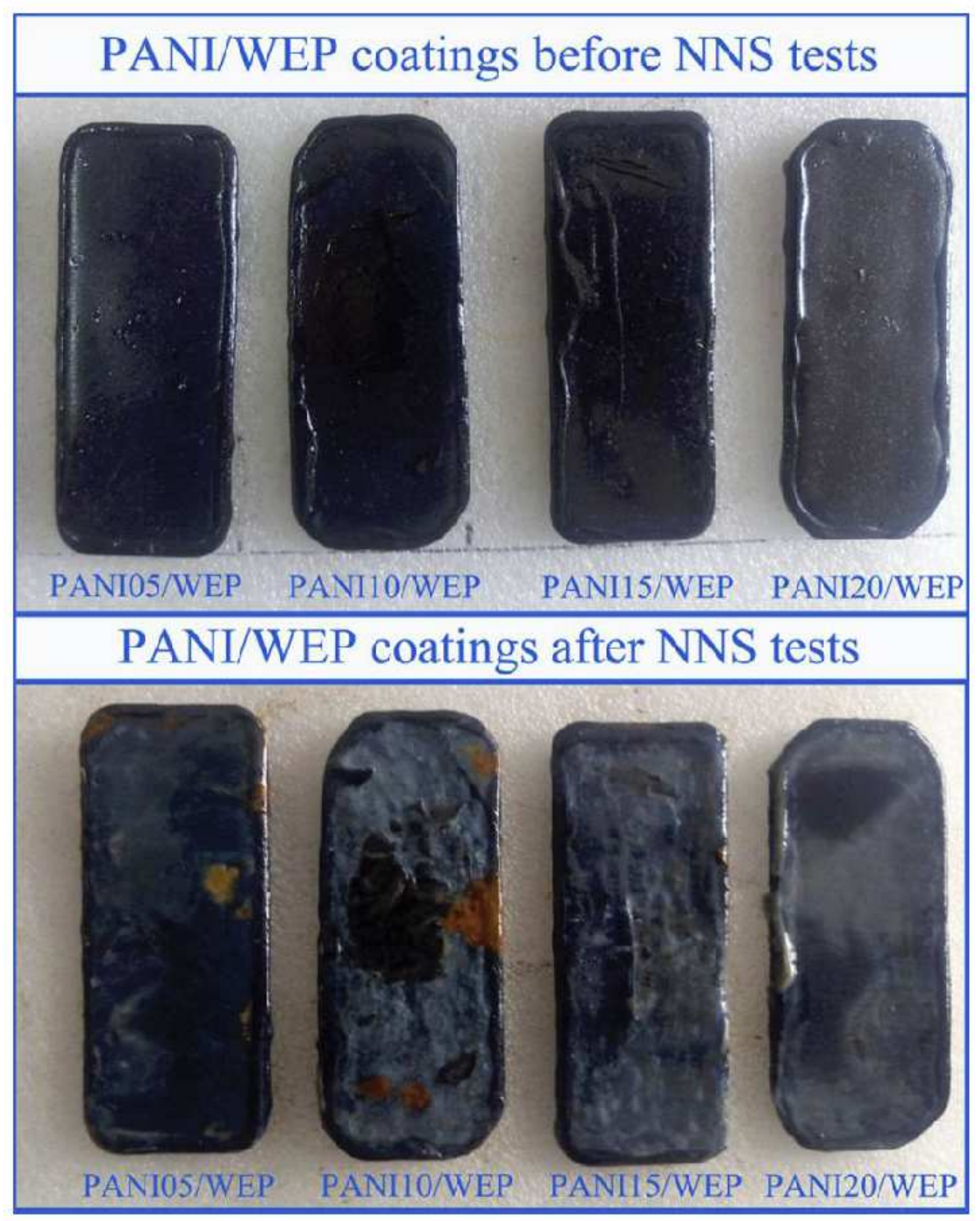

Figure 8

Photographs of PANI/WEP composite coatings before and after salt spray tests 


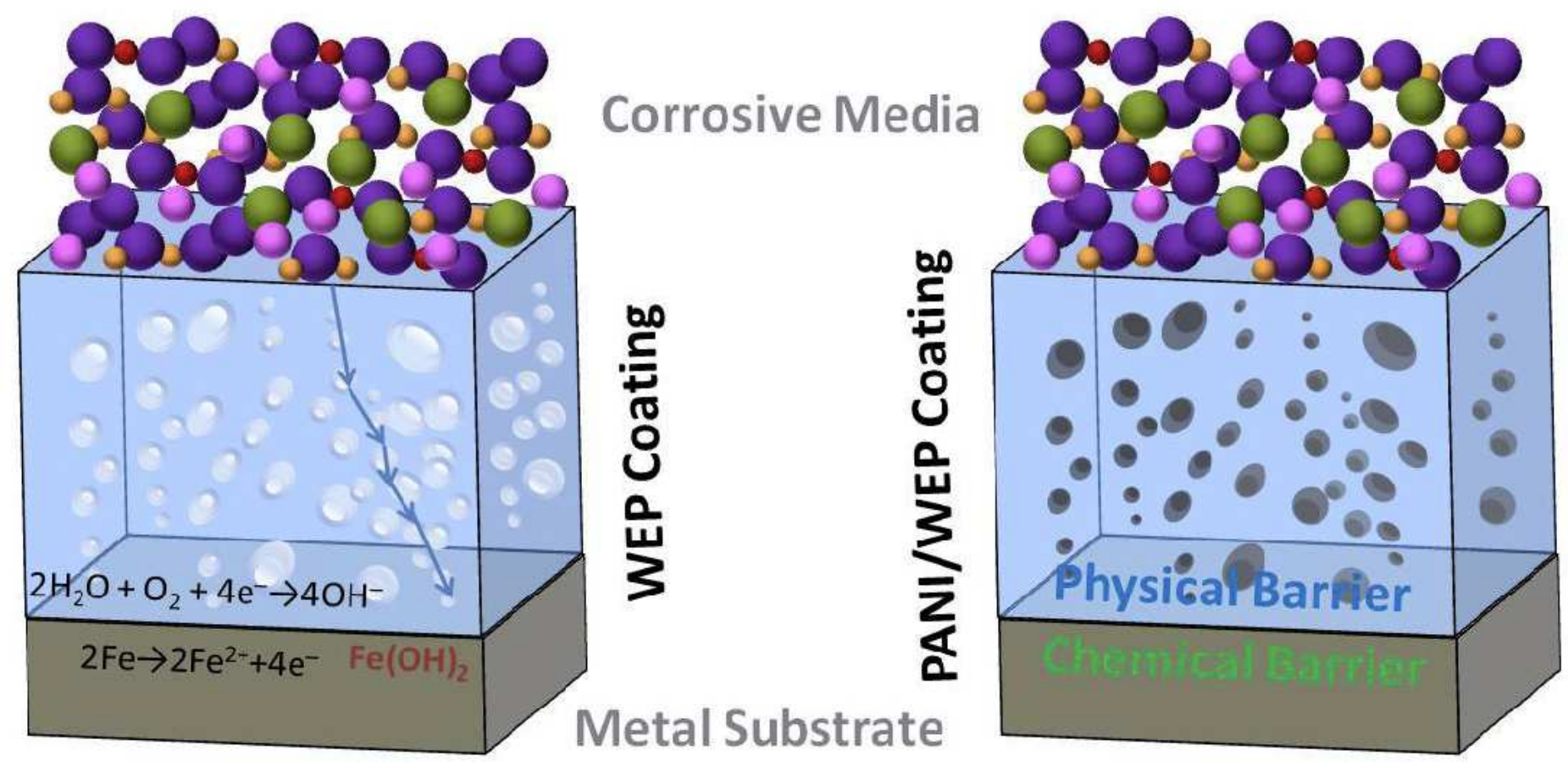

Figure 9

Enhanced anticorrosive mechanism of WEP coating by the addition of PANI 